\title{
Combined Fistulotomy and Contralateral Anal Internal Sphincterotomy for Recurrent and Complex Anal Fistula to Prevent Recurrence
}

\author{
Adeodatus Yuda Handaya ${ }^{1,2}$, Aditya Rifqi Fauzi ${ }^{2}$ \\ ${ }^{1}$ Division of Digestive Surgery, Department of Surgery, Dr. Sardjito Hospital, Yogyakarta; ${ }^{2}$ Faculty of Medicine, Universitas Gadjah Mada, \\ Yogyakarta, Indonesia
}

The ideal intervention in the treatment of perianal fistula prevents the onset of infection to speed healing and prevent fistula recurrence while maintaining the function of the anal sphincter. Currently, there is no consensus on the best recommended surgical technique for perianal fistula management. Several studies have shown that fistulotomy was an easy and safe procedure for treatment of perianal fistula. Lateral internal sphincterotomy is the usual procedure performed on an anal fissure to decrease the anal sphincter tone. This study reports a combination of fistulotomy and contralateral internal sphincterotomy procedures for recurrent and complex perianal fistula to prevent recurrence. Here, we report 5 cases of recurrent and complex perianal fistula. The combination of fistulotomy and contralateral internal sphincterotomy is a relatively easy and safe procedure for complex perianal fistulae. In our cases, we found neither recurrence nor postoperative anal incontinence.

\section{Keywords: Anal fistula; Complex; Recurrence; Fistulotomy; Anal internal sphincterotomy}

\section{INTRODUCTION}

Perianal fistula is the formation of an epithelized track between the rectum or anal canal and the perianal region. The most common cause, in as many as $90 \%$ of cases, is an infection of the cryptoglandular gland, and the remainder of the cases involve Crohn disease, trauma, malignancy, or radiotherapy. The incidence is 8.6 in 100,000 population of the world, while those in Italy and Spain are 10.4 and 23.2 in 100,000 patients, respectively. The sex ratio is $2: 1$ for males compared to females, and the age range is $30-50$ years. In the United States, 68,000 to 96,000 new cases are reported annually [1]. Patients with perianal fistula usually complain of

Received: May 26, 2018 - Accepted: November 19, 2018

Correspondence to: Adeodatus Yuda Handaya, M.D.

Division of Digestive Surgery, Department of Surgery, Faculty of Medicine, Universitas Gadjah Mada, Dr. Sardjito Hospital, Jl. Kesehatan No. 1

Yogyakarta 55281, Indonesia

Tel \& Fax: +62274581333, E-mail: yudahandaya@ugm.ac.id

ORCID: https://orcid.org/0000-0003-0256-1955

(C) 2020 The Korean Society of Coloproctology

This is an open-access article distributed under the terms of the Creative Commons Attribution NonCommercial License (https://creativecommons.org/licenses/by-nc/4.0) which permits unrestricted non-

commercial use, distribution, and reproduction in any medium, provided the original work is properly cited. feeling fluid exit the anus with dirty, wet, and odorous underwear that causes discomfort and affects quality of life [2]. The diagnosis is made when an external opening in the perianal region is discovered on clinical examination. Fistulography, magnetic resonance imaging, or endorectal sonography can be employed to support the diagnosis [3]. According to the American Society of Colorectal Surgeons, complex perianal fistula is classified as intersphincteric, transsphincteric, or supra-sphincteric fistula [4-6].

Surgical management of perianal fistula involves removal of the internal opening of the rectum or anal canal and the track to the perianal region. The surgery can be performed in several ways. Invasive methods include fistulotomy and fistulectomy, as well as less invasive surgeries aimed to reduce the risk of sphincter injury with the use of a plug, fibrin glue, mucosal advancement, and ligation of the intersphincteric fistulous tract (LIFT) and video-assisted anal fistula surgery [1].

Management of perianal fistula using a seton has a risk of recurrence primarily due to extension of the supralevator, horseshoetype perianal fistula, and history of previous perianal fistula surgery. Another option of perianal fistula management is fistulectomy, but this procedure requires longer wound healing and carries the same recurrence risk as fistulotomy [7]. 
In cases of anal fissure, administration of medications that can temporarily relax the anal sphincter decrease anorectal pressure to accelerate wound healing, and the effects are reversible after the drugs are depleted or discontinued. In cases of perianal fissure, however, the medication is continued to maintain low anorectal pressure after the wound of the fissurotomy had healed $[1,2]$.

The management principles for complex perianal fistula include treatment of infections, elimination of fistula tracks, prevention of recurrence, and avoidance of anal incontinence with minimal complications and short duration of hospital care. For inter- and transsphincteric fistula, fistulotomy accompanied by splicing of the anal sphincter is the preferred surgical method, followed by open wound treatment. The recurrence rate for fistulotomy is between $0 \%-21 \%$ of cases, with a $0 \%-82 \%$ incidence of incontinence. For complex perianal fistula, fistulotomy is contraindicated in patients with high-lying fistulae involving most of the internal and external anal sphincter and in women with an anterior anal fistula caused by Crohn disease (because of the risk of occurrence of fissure due to an impaired healing process caused by long-term steroids) $[3,6]$.

Because of the high recurrence rate and many repetitive surgeries, management of perianal fistula is expensive, leading to dissatisfaction in the service and management of perianal fistula. There are some alternative procedures in the handling of both simple and complex perianal fistulae, but because of the high rates of recurrence and incontinence, there is no consensus or agreement on surgical technique. The relatively new technique of LIFT has a $30 \%-60 \%$ recurrence rate, and plugging of the anal fistula has a $70 \%-80 \%$ recurrence rate, while the recurrence rate in "cutting Seton" and endorectal flap advancement have 30\%-60\% therapeutic failure with risk of incontinence up to $67 \%$. According to Aarons, in a single, large center study, the recurrence rate of the fistulotomy technique was only $2 \%$ lower than other techniques. Temporary incontinence occurred in 3\% of the fistulotomy patients in 72 months of postoperative follow-up and evaluation [8].

The recurrence of perianal fistula may be due to spasm and hypertonia persisting in the internal anal sphincter, which will interfere with the blood flow in fistulotomy wounds, resulting in disruption of the wound healing process and increased risk of recurrence $[8,9]$.

\section{Combined fistulotomy and lateral internal sphincterotomy procedure}

Management of perianal fistula by a combination of fistulotomy and lateral internal sphincterotomy aims to reduce spasm and hypertonia to increase blood flow to the wound after fistulotomy, improving wound healing. In our hospital, preoperative and postoperative pressure tone were performed using digital rectal examination. Preoperatively, if 1 or 2 finger(s) can be inserted into the anal canal, the sphincter is tight. After surgery, if up to 2-3 fingers can be inserted, the sphincter had been loosened. Manometry examination was not performed preoperatively because patients were in pain due to infection or abscess. Postoperatively, manometry examination was not performed because of postoperative pain.

\section{Operative technique}

1. After explaining that the perianal fistula will be treated with a combination of fistulotomy and a lateral internal sphincterotomy, obtain verbal and written informed consent from the patient. Do not share the informed consent data.

2. Prepare the bowel with Fleet Phospho-soda (Combiphar, Jakarta, Indonesia) liquid on the night before surgery and Fleet enema the morning of surgery. Administer antibiotics (IV ceftriaxone $1 \mathrm{~g}$ and metronidazole $500 \mathrm{mg}$ ) one day before surgery.

3. Conduct regional anesthesia and place the patient in the lithotomy position.

4. Perform a physical examination with anoscope to ensure there are no perianal abscesses.

5. Insert a mixture of hydrogen peroxide $30 \%$ and methylene blue into the external opening on the posterior of the anus to determine the internal opening, which is marked by a discharge of blue frothing liquid.

6. Perform the first stage: the fistulotomy procedure. Place a fistula sonde from the external opening to the internal opening and make an incision using electrocautery to cut the internal and external openings of the fistula canal. Wounds to the skin and anodermal layers are left open, and secondary healing is expected.

7. Perform the second stage: lateral internal anal sphincterotomy. Cut the skin $2 \mathrm{~cm}$ above the sphincter at 5 oclock, perform lateral identification of the internal anal sphincter with a clamp, then cut the sphincter (Fig. 1). Close the skin with an intracutaneous suture using vicryl 2-0 in order to lay open the fistula.

8. Apply tampon to the anal canal and gauze covered with chloramphenicol ointment to the fistulotomy wounds.

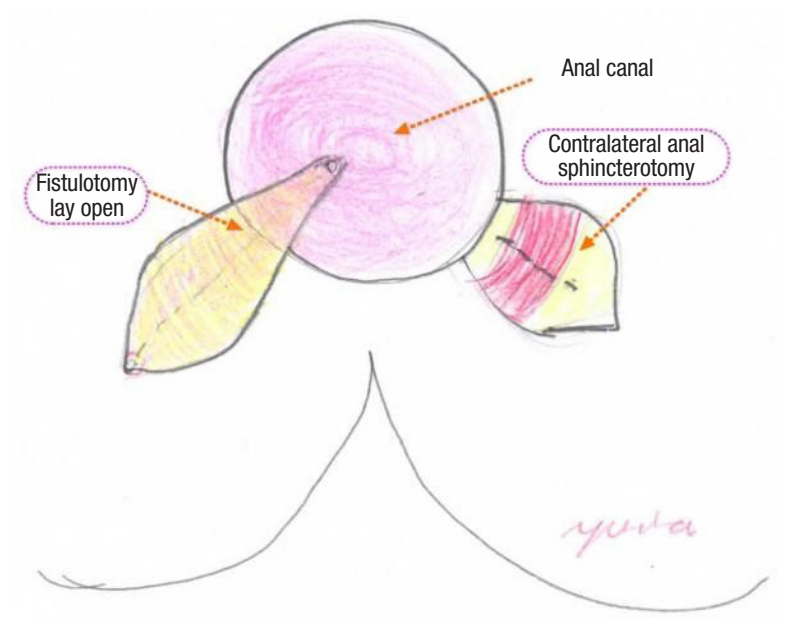

Fig. 1. Combination of fistulotomy and contralateral internal sphincterotomy. 


\section{Postoperative management}

1. On the first postoperative day, the patient may drink as usual and eat porridge. Also, administer the following intravenous (IV) antibiotics: (IV) ceftriaxone $1 \mathrm{~g}$ twice a day, metronidazole $500 \mathrm{mg} 3$ times a day, and ketorolac $40 \mathrm{mg} 3$ times a day.

2. On the second postoperative day, remove the anal tampon and apply antiseptic soaked with potassium permanganate.

3. On the third postoperative day, continue the antiseptic soaked with potassium permanganate and add an ointment of chloramphenicol, allowing the healing process to occur naturally from the base of the wound to the surface or to the mucosa or anal canal.

4. One week postoperative, perform a digital rectal examination and anal dilatation and apply chloramphenicol ointment during a follow-up appointment at the polyclinic.

5. Continue to postoperatively evaluate the patient in the second week and 2 months at the polyclinic. At the sixth postoperative month, contact the patient via telephone to evaluate wound healing, pain, presence or absence of incontinence, and recurrence.

\section{CASE REPORTS}

This study has been approved by the Institutional Review Board of the Faculty of Medicine, Universitas Gadjah Mada under permit KE/FK/0955/EC/2018. The authors attest that full and informed consent was obtained from every patient who has undergone medical treatment in our hospital. The informed consent form declared that patient data or samples will be used for educational or research purposes.

\section{Case 1}

A 30-year-old male presented to our clinic with complaints of discharge on the rim of the anus. The patient had a history of fistulotomy surgery three times. The patient was diagnosed with complex anal fistula. Combined fistulotomy and lateral internal sphincterotomy were conducted to manage the complex perianal fistula. During the operation, estimated bleeding was around 50 $\mathrm{mL}$, and the operation length was 45 minutes. Postoperatively, the patient was given intravenous ceftriaxone $1 \mathrm{~g}$ twice a day. The patient was hospitalized for three days. At the postoperative followup appointment at the polyclinic on day 7 , the patient said that he had experienced pain for about 7 days, and there was anal incontinence. The patient continued to experience anal incontinence at the 14-day follow-up appointment. At the 1- and 6-month followup appointments, the patient had no bleeding, infection, recurrence, or anal incontinence.

\section{Case 2}

A 38-year-old male presented to our clinic with complaint of discharge on the rim of the anus. The patient had a history of fistulotomy surgery 2 times. The patient was diagnosed with complex anal fistula, as shown in Fig. 2A. Combined fistulotomy and lateral internal sphincterotomy were conducted to manage the complex perianal fistula, as seen in Fig. 2B. Estimated perioperative bleeding was around $75 \mathrm{~mL}$, and the operation length was 1 hour. Postoperatively, the patient intravenously received ceftriaxone $1 \mathrm{~g}$ twice a day and metronidazole $500 \mathrm{mg}$ twice a day. The patient was hospitalized for 3 days. At the postoperative follow-up appointment at the polyclinic on day 7 , the patient said he had pain for about 7 days, and there was anal incontinence. The patient continued to experience anal incontinence at the 14-day followup appointment. At the 1-month (Fig. 2C), 2-month (Fig. 2D), and 6-month follow-up appointments, the patient had no bleeding, infection, recurrence, or anal incontinence.

\section{Case 3}

A 36-year-old male presented to our clinic with complaints of discharge on the rim of the anus. The patient had a 1-time history of fistulotomy surgery. The patient was diagnosed with recurrent anal fistula. The surgical procedure was performed to manage the patient. During the operation, estimated blood loss was around $75 \mathrm{~mL}$, and the operation length was 1 hour. Postoperatively, the patient was given intravenous ceftriaxone $1 \mathrm{~g}$ twice a day. The patient was hospitalized for 2 days. At the postoperative follow-up appointment at the polyclinic on day 7 , the patient said he had pain for about 4 days, and there was anal incontinence. The patient continued to experience anal incontinence at the 14-day follow-up appointment. At the 1- and 6-month follow-up appointments, the patient had no bleeding, infection, recurrence, or anal incontinence.

\section{Case 4}

A 34-year-old male presented to our clinic with complaints of discharge on the rim of the anus. The patient had no history of surgery. The patient was diagnosed with complex anal fistula. Combined fistulotomy and lateral internal sphincterotomy were conducted to manage the complex perianal fistula. During the operation, the estimated bleeding was around $50 \mathrm{~mL}$, and the operation length was 1 hour. Postoperatively, the patient was given intravenous ceftriaxone $1 \mathrm{~g}$ twice a day. The patient was hospitalized for 3 days. At the postoperative follow-up appointment at the polyclinic on day 7 , the patient complained of pain for about 5 days, and there was anal incontinence. The patient continued to experience anal incontinence at the 14-day follow-up appointment. At the 1- and 6-month follow-up appointments, anal incontinence persisted. The patient was still experiencing anal incontinence at 14 weeks postoperative.

\section{Case 5}

A 36-year-old male presented to our clinic with complaints of discharge on the rim of the anus. The patient had a history of one fistulotomy surgery. The patient was diagnosed with recurrent anal fistula, as seen in Fig. 3A. Combined fistulotomy and lateral 

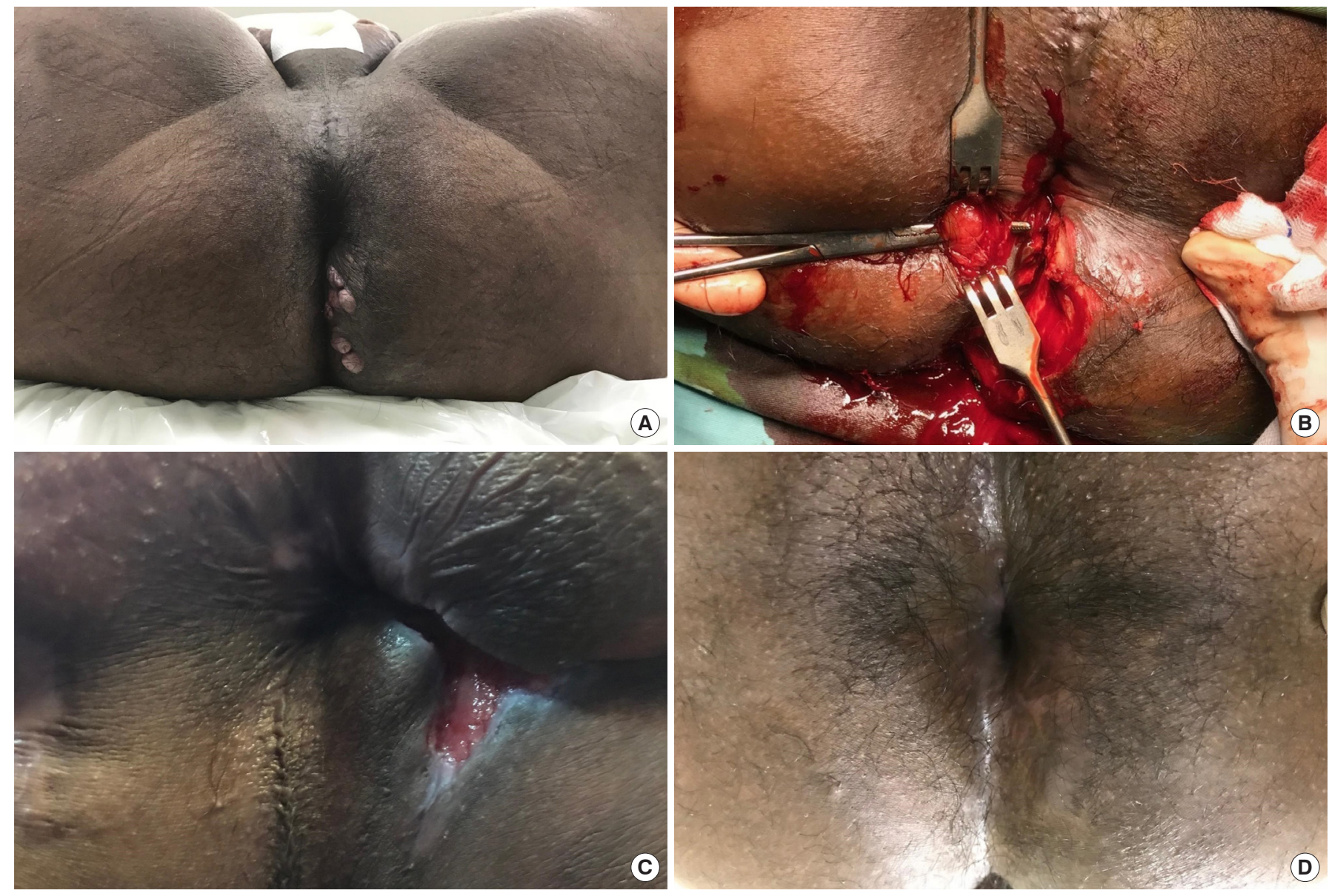

Fig. 2. Complex anal fistula. (A) Preoperative state with multiple complex anal fistulae, (B) intraoperative state, (C) 1-month postoperative follow-up, and (D) 2-month postoperative follow-up.

internal sphincterotomy were conducted to manage the recurrent anal fistula as in Fig. 3B. During the operation, estimated blood loss was around $50 \mathrm{~mL}$, and the operation length was 45 minutes. Postoperatively, the patient was given intravenous ceftriaxone $1 \mathrm{~g}$ twice a day. The patient was hospitalized for 2 days. At the postoperative follow-up appointment at the polyclinic on day 7 , as seen in Fig. 3C, the patient stated he had pain for about 3 days, and there was anal incontinence. The patient had no anal incontinence at the 14-day follow-up appointment. At the 1-month, 3-month (Fig. 3D), and 6-month follow-up appointments, the patient had no bleeding, infection, recurrence, or anal incontinence.

Here we present a summary table of the characteristics from each case (Table 1).

\section{DISCUSSION}

Our hospital is a national referral hospital, and we often receive patients with residual or complex perianal fistulae that cannot be effectively managed in lower-grade hospitals. Perianal fistula, a colorectal disorder that is so clinically and psychologically disturbing that it requires comprehensive treatment, has an incidence rate of 10/1,000 people around the world. Our patients usually complain of fluid at the edges of the anus, itching, and sometimes pain with fever due to recurrent perianal infections or abscesses. The management of perianal fistula in surgical techniques and nonoperative management is challenging due to high recurrence and postoperative fecal incontinence [6]. At our referral hospital, $60 \%$ of patients present with recurrence, $30 \%$ have a simple fistula, and $10 \%$ of patients present with a complex fistula.

The postsurgical incidence rate of anal incontinence varies as follows: $0 \%-25 \%$ of patients suffer from flatus incontinence, $0 \%-$ $17 \%$ suffer from fecal incontinence, and more than $40 \%$ suffer from passive incontinence. The incidence of incontinence depends on the type of surgical procedure, the type and complexity of the fistula, the presence of risk factors for incontinence (age, sex, history of operations before the onset perianal fistula), and other factors. With a success rate of wound healing ranging from $74 \%-100 \%$, fistulotomy is still the preferred surgical technique for 
Annals of Combined Fistulotomy and Contralateral Anal Internal Sphincterotomy for Recurrent and Complex Coloproctology Adeodatus Yuda Handaya, et al.
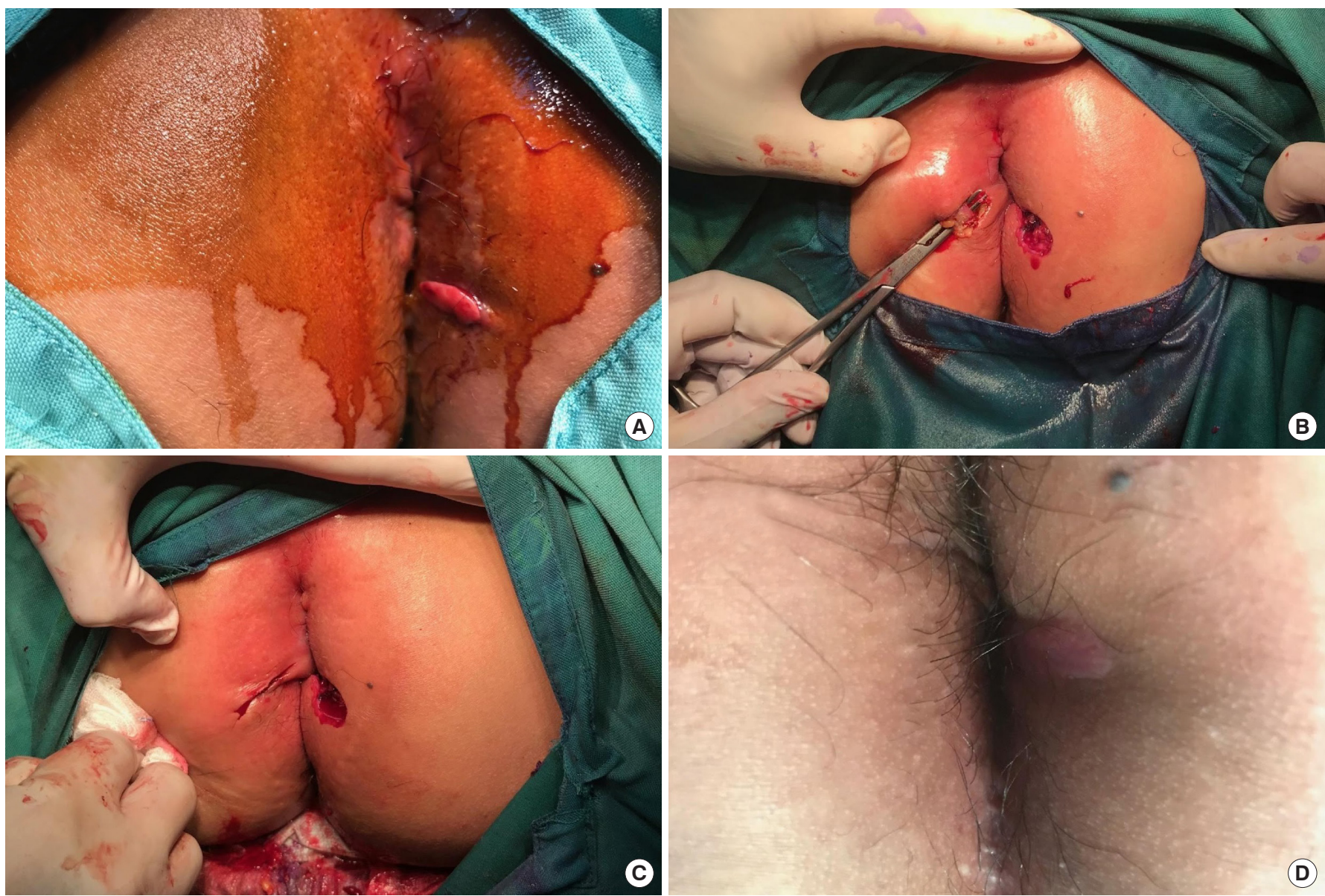

Fig. 3. Recurrent anal fistula. (A) Preoperative state, (B) intraoperative state, (C) postoperative state, and (D) 3-month follow-up.

Table 1. Case summary

\begin{tabular}{|c|c|c|c|c|c|c|c|c|c|c|c|}
\hline \multirow[b]{2}{*}{ No } & \multirow[b]{2}{*}{ Sex } & \multirow{2}{*}{$\begin{array}{l}\text { Age } \\
\text { (yr) }\end{array}$} & \multirow[b]{2}{*}{ Diagnosis } & \multirow{2}{*}{$\begin{array}{l}\text { External } \\
\text { opening }\end{array}$} & \multirow{2}{*}{$\begin{array}{l}\text { Internal } \\
\text { opening }\end{array}$} & \multirow[b]{2}{*}{ Cause } & \multirow{2}{*}{$\begin{array}{c}\text { Previous } \\
\text { surgery }\end{array}$} & \multicolumn{4}{|c|}{ Postoperative (follow-up) } \\
\hline & & & & & & & & Fistula type & $\begin{array}{l}\text { Duration of } \\
\text { pain }\end{array}$ & $\begin{array}{l}\text { Duration of } \\
\text { incontinence }\end{array}$ & Recurrence \\
\hline 1 & Male & 30 & $\begin{array}{l}\text { Complex anal } \\
\text { fistula }\end{array}$ & $\begin{array}{c}\text { Single right } \\
\text { posterior }\end{array}$ & $\begin{array}{l}\text { Single right } \\
\text { posterior }^{\mathrm{a}}\end{array}$ & $\begin{array}{l}\text { Infection/perianal } \\
\text { abscess }\end{array}$ & 3 Times & Transsphincteric & 5 Days & 14 Days & No \\
\hline 2 & Male & 38 & $\begin{array}{l}\text { Complex anal } \\
\text { fistula }\end{array}$ & $\begin{array}{l}\text { Single left } \\
\text { posterior }\end{array}$ & $\begin{array}{l}\text { Single left } \\
\text { posterior }^{\mathrm{a}}\end{array}$ & $\begin{array}{l}\text { Infection/perianal } \\
\text { abscess }\end{array}$ & 2 Times & Transsphincteric & 7 Days & 14 Days & No \\
\hline 3 & Male & 36 & $\begin{array}{l}\text { Recurrent } \\
\text { anal fistula }\end{array}$ & $\begin{array}{l}\text { Multiple (6) } \\
\text { left posterior }\end{array}$ & $\begin{array}{l}\text { Single left } \\
\text { posterior }^{\mathrm{a}}\end{array}$ & $\begin{array}{l}\text { Infection/perianal } \\
\text { abscess }\end{array}$ & 1 Time & Transsphincteric & 4 Days & 14 Days & No \\
\hline 4 & Male & 34 & $\begin{array}{l}\text { Complex anal } \\
\text { fistula }\end{array}$ & $\begin{array}{l}\text { Multiple (2) } \\
\text { right posterior }\end{array}$ & $\begin{array}{r}\text { Single right } \\
\text { posterior }^{\mathrm{a}}\end{array}$ & $\begin{array}{l}\text { Infection/perianal } \\
\text { abscess }\end{array}$ & No & Transsphincteric & 5 Days & 14 Weeks & No \\
\hline 5 & Male & 50 & $\begin{array}{l}\text { Recurrent } \\
\text { anal fistula }\end{array}$ & $\begin{array}{l}\text { Single left } \\
\text { posterior }\end{array}$ & $\begin{array}{l}\text { Single left } \\
\text { posterior }^{\mathrm{a}}\end{array}$ & $\begin{array}{l}\text { Infection/perianal } \\
\text { abscess }\end{array}$ & 1 Time & Transsphincteric & 3 Days & 10 Days & No \\
\hline
\end{tabular}

${ }^{a}$ Above the dentate line.

treatment of perianal fistula, although there have been reported recurrences and occurrences of anal incontinence in cases of complex perianal fistulae [6]. Other research described the LIFT technique as safe and easy to perform, with low morbidity, no occurrence of incontinence, and a success rate greater than 70\% [7]. In the present case report, we described patients with both re- 
current and complex perianal fistulae who presented with both initial and relapsed fistulae, and we performed a combination fistulotomy with lateral internal sphincterotomy to maximally decrease the anorectal pressure to facilitate wound healing from sufficient blood flow as well as prevent recurrence. The major postoperative complaint from patients is pain in the perianal region approximately 1 week after surgery. Two weeks after treatment, the wound from the lateral internal sphincterotomy is closed, and the wounds from fistulotomy with open treatment will close at 6 weeks. The primary outcome was complete healing, and the secondary outcome was freedom from incontinence. The patients reported easier defecation and no need to hard strain, a risk factor for anal mucosa laceration, abscess infection, and recurrence of perianal fistulae. Furthermore, the present report is a preliminary study for the surgical techniques in the treatment of complex and recurrent perianal fistulae. Further large-scale studies are needed to strengthen the evidence.

In conclusion, our primary study report showed that the combination of fistulotomy and lateral internal sphincterotomy is a safe procedure for recurrent and complex perianal fistulae. In 6 months of follow-up, there were no reports of recurrence or incontinence. Furthermore, a multicenter study with a larger sample of patients and longer follow-up data is necessary to clarify and confirm our findings.

\section{CONFLICT OF INTEREST}

No potential conflict of interest relevant to this article was reported.

\section{ACKNOWLEDGMENTS}

We thank the surgical team and the nursing staff who were involved in patient care and surgeries.

\section{REFERENCES}

1. Mendes CR, Ferreira LS, Sapucaia RA, Lima MA, Araujo SE. VAAFT - Video assisted anal fistula treatment: a new approach for anal fistula. J Coloproctol (Rio J) 2014;34:62-4.

2. Lundqvist A, Ahlberg I, Hijalte F, Ekelund M. Direct and indirect costs for anal fistula in Sweden. Int J Surg 2016;35:129-33.

3. Carvalho AL, Filho EF, Alcantara RS, Barreto MD. FILAC-Fistula-Tract Laser Closure: a sphincter-preserving procedure for the treatment of complex anal fistulas. J Coloproctol (Rio J) 2017;37: 160-2.

4. Shanmugan S, Champagne BJ. Anal fistula plug: where were we, where are we now? Semin Colon Rectal Surg 2014;25:186-9.

5. Hazim W, Al-Ozaibi L, Azam H, Al-Mazrouei A, Al-Badri F. Anal fistula surgery in an outpatient setting: the Dubai experience. J Coloproctol (Rio J) 2015;35:42-5.

6. Anaraki F, Etemad O, Abdi E, Bagherzadeh G, Behboo R. Assessment of fistulectomy combined with sphincteroplasty in the treatment of complicated anal fistula. J Coloproctol (Rio J) 2017;37: 232-7.

7. Emile HE, Elfeki H, Thabet W, Sakr A, Magdy A, El-Hamed TM, et al. Predictive factors for recurrence of high transsphincteric anal fistula after placement of seton. J Surg Res 2017;213:261-8.

8. Aarons CB. The use of biologics in anal fistulae. Semin Colon Rectal Surg 2014;25:206-9.

9. Salih AM. Chronic anal fissures: open lateral internal sphincterotomy result; a case series study. Ann Med Surg (Lond) 2017;15: 56-8. 